\title{
Examining 30-day COPD readmissions through the emergency department
}

This article was published in the following Dove Press journal: International Journal of COPD

\author{
Michael E Rezaee' \\ Charlotte E Ward ${ }^{2,3}$ \\ Bonita Nuanez' \\ Daniel A Rezaee ${ }^{4}$ \\ Jeffrey Ditkoff',5 \\ Alexandra Halalau ${ }^{1,6}$ \\ 'Oakland University William \\ Beaumont School of Medicine, \\ Rochester, MI, ${ }^{2}$ Center for Healthcare \\ Studies, Feinberg School of Medicine, \\ Northwestern University, ${ }^{3}$ Center \\ for Health Statistics, University of \\ Chicago, Chicago, IL, "Primary Care, \\ Brigham and Women's Hospital, \\ Boston, MA, ${ }^{5}$ Emergency Medicine, \\ 'Internal Medicine, Beaumont Health, \\ Royal Oak, MI, USA
}

Background: Thirty-day readmission in COPD is common and costly, but potentially preventable. The emergency department (ED) may be a setting for COPD readmission reduction efforts.

Objective: To better understand COPD readmission through the $\mathrm{ED}$, ascertain factors associated with 30-day readmission through the ED, and identify subgroups of patients with COPD for readmission reduction interventions.

Patients and methods: A retrospective cohort study was conducted from January 2009 to September 2015 in patients with COPD of age $\geq 18$ years. Electronic health record data were abstracted for information available to admitting providers in the ED. The primary outcome was readmission through the ED within 30 days of discharge from an index admission for COPD. Logistic regression was used to examine the relationship between potential risk factors and 30-day readmission.

Results: The study involved 1,574 patients who presented to the ED within 30 days on an index admission for COPD. Of these, $82.2 \%$ were readmitted through the ED. Charlson score (odds ratio [OR]: 3.6; 95\% CI: 2.9-4.4), a chief complaint of breathing difficulty (OR: $1.6 ; 95 \% \mathrm{CI}$ : 1.1-2.6), outpatient utilization of albuterol (OR: 4.1; 95\% CI: 2.6-6.4), fluticasone/salmeterol (OR: 2.3; 95\% CI: 1.3-4.2), inhaled steroids (OR: 3.8; 95\% CI: 1.3-10.7), and tiotropium (OR: 1.8; 95\% CI: 1.0-3.2), as well as arterial blood gas (OR: 4.4; 95\% CI: 1.3-15.1) and B-type natriuretic peptide (OR: 2.2; 95\% CI: 1.4-3.5) testing in the ED were associated with readmission (c-statistic $=0.936$ ). Seventeen-point-eight percent of patients with COPD presented to the ED and were discharged home; $56 \%$ presented with a complaint other than breathing difficulty; and $16 \%$ of those readmitted for breathing difficulty had a length of stay $<48$ hours.

Conclusion: Intensive outpatient monitoring, evaluation, and follow-up after discharge are needed to help prevent re-presentation to the ED, as practically all patients with COPD who re-present to the ED within 30 days are readmitted to the hospital and for a variety of clinical complaints. Among those patients with COPD who present with breathing difficulty, improved decision support algorithms and alternative management strategies are needed to identify and intervene on the subgroup of patients who require $<48$-hour length of stay.

Keywords: COPD, readmission, emergency department, dyspnea, length of stay, observation study, epidemiology, hospital admission

\section{Background}

COPD is a prevalent disease that is of immense concern to the US public health and health care systems. An estimated 24 million Americans (7.5\%) suffer from COPD, with the highest prevalence of disease being found in the states of Michigan (7.4\%), Tennessee (8.7\%), Alabama (9.1\%), and Kentucky (9.3\%). ${ }^{1}$ The economic burden of COPD is significant. In 2010, the cost of COPD was $\$ 49.9$ billion or $\sim \$ 4,000$ per patient per year. ${ }^{2}$ Hospital admissions and readmissions for patients with COPD
Correspondence: Alexandra Halalau Oakland University William Beaumont School of Medicine, 3535 W. I3 Mile Road, Royal Oak, MI 48073, USA

$\mathrm{Tel}+\mathrm{I} 24855$ I 0457

Fax + I 24855 I 1245

Email alexandra.halalau@beaumont.edu
International Journal of COPD 2018:13 109-120 Dovepress f in http://dx.doi.org// 0.21 477/COPD.S147796 (c) (1) (-) 2018 Rezaee et al. This work is published and licensed by Dove Medical Press Limited. The full terms of this license are available at https://www.dovepress.com/terms.php cc) ${ }_{\mathrm{BY}} \mathrm{NC}$ and incorporate the Creative Commons Attribution - Non Commercial (unported, v3.0) License (http://creativecommons.org/licenses/by-nc/3.0/). By accessing the work you hereby accept the Terms. Non-commercial uses of the work are permitted without any further permission from Dove Medical Press Limited, provided the work is properly attributed. For permission for commercial use of this work, please see paragraphs 4.2 and 5 of our Terms (https://www.dovepress.com/terms.php). 
are high, are on the rise, and have become a focus of pay-forperformance and quality improvement programs. ${ }^{3}$ Published evidence has shown a 7.1\% 30-day readmission rate for a principal diagnosis of COPD and $20.5 \%$ for all-cause 30 -day readmission among discharged patients with COPD. ${ }^{4}$

Interventions have attempted to reduce COPD readmissions. ${ }^{5}$ However, currently, there is inadequate evidence to endorse specific recommendations to reduce readmissions among patients with COPD. ${ }^{5}$ Despite a lack of explicit guidance, establishment of the Medicare Hospital Readmission Reduction Program (MHRRP) has prompted hospitals to examine and intervene all aspects of COPD patients' care, including their re-entry into the hospital through the emergency department (ED). ${ }^{6}$

Decision support algorithms are available to physicians to assist in determining appropriate hospital admission vs observation and/or discharge home in COPD. ${ }^{7-12}$ However, the adoption and utility of these tools is unclear, and decisions to admit patients with COPD are often based on clinical judgment. With increasing attention on the ED as a potential setting to reduce 30-day COPD readmissions, our objectives were to better understand COPD readmission through the ED, ascertain clinical and demographic factors driving decisions to readmit patients to the hospital through the ED, and identify subgroups of patients with COPD for potential readmission reduction efforts.

\section{Patients and methods Study design}

A retrospective cohort study was conducted on all patients presenting with COPD of age $\geq 18$ years from Beaumont Health (BH) between January 1, 2009 and September 30, 2015. $\mathrm{BH}$ is a large health care system serving patients across southeastern Michigan, including greater Detroit. To be included, the criteria were as follows: 1) patients discharged from an inpatient stay with an index diagnosis of COPD, 2) patients who presented to the ED for any reason within 30 days of discharge, and 3) those who were readmitted through the ED or discharged home from the ED within 30 days of discharge. International Classification of Diseases, Ninth Revision, Clinical Modification (ICD-9-CM) codes were used to identify patients with COPD: 491-491.22, 492-492.8, 493.2, and 496. All patient data utilized for this study were deidentified prior to obtainment and analysis. The BH Research Institute for Human Investigation Committee approved this study (institutional review board number 2015-443). This manuscript was prepared in accordance with Transparent Reporting of a multivariable prediction model for Individual
Prognosis or Diagnosis and Strengthening the Reporting of Observational Studies in Epidemiology. ${ }^{13,14}$

BH's electronic health record (EHR; Epic Systems, Verona, WI, USA) was queried between the study dates to identify patients meeting the inclusion criteria and to obtain the clinical, demographic, and outcome data necessary for the analysis. It was possible for patients to have multiple COPD admissions and readmissions during the study period. To ensure that we analyzed unique patients, we limited the sample to only the first occurrence of when a patient visited the ED within 30 days of a discharge for COPD.

\section{Outcomes}

The primary outcome of this study was readmission through the ED within 30 days of discharge from an index admission for COPD. Second, we examined readmission through the ED within 30 days of discharge from an index admission for COPD for patients who presented with a chief complaint of breathing difficulty. Third, among patients with COPD who were readmitted within 30 days through the ED, we evaluated predictors for readmission length of stay (LOS) $\geq 48$ hours.

\section{Predictors}

Clinical and demographic variables were identified based on the clinical input of the authors. Clinical data included, but were not limited to, arterial blood gas (ABG) testing, B-type natriuretic peptide (BNP) testing and results, weight (kg), height (m), Glasgow Coma Score, presenting and lastcollected vital signs, oxygen saturation, $\mathrm{FiO}_{2} \%, \mathrm{O}_{2}(\mathrm{~L} / \mathrm{min})$ supplementation, method of $\mathrm{O}_{2}$ delivery, Charlson score, prescribed outpatient COPD medications, chief complaint in ED, time to ED visit (days), time in ED (hours), length of prior inpatient stay (days), and length of second inpatient stay (days). Demographic data included age (years), gender, race/ethnicity, primary insurance, marital status, smoking status, and smoking pack years (packs/year).

\section{Statistical analysis}

Patients with missing covariates were excluded to conduct a complete case analysis. Univariate analyses were used to examine characteristics by 30 -day readmission status. All factors associated with 30-day readmission through the ED in univariate analyses were used to build a multivariate logistic regression model, where the outcome was modeled as a binary indicator (ie, whether the patient was admitted to the hospital through the ED or not). A $P$-value of 0.25 was used as a cutoff for inclusion in the final model, as more traditional levels such as 0.05 can fail in identifying variables 
known to be important. ${ }^{15,16}$ Certain patient characteristics (ie, age, gender, insurance, and smoking) were incorporated into the model regardless of univariate statistical significance, as they have previously been identified as risk factors for readmission. ${ }^{7-12}$ The c-statistic was used to approximate the predictive validity of the model. ${ }^{17}$

Next, we limited the sample to patients presenting to the ED within 30 days with a chief complaint of breathing difficulty. The purpose of this analysis was to identify potential predictors of 30-day readmission among patients with likely COPD exacerbation vs those with chief complaints unrelated to their underlying COPD.

Finally, we examined potential predictors of a readmission LOS $\geq 48$ hours among patients readmitted with breathing difficulty. The goal of this analysis was to identify features that have a relationship with LOS. All analyses were performed using SAS 9.4 (SAS Institute, Cary, NC, USA).

\section{Ethics approval and consent}

All procedures performed in studies involving human participants were in accordance with the ethical standards of the $\mathrm{BH}$ Research Institute for Human Investigation Committee and with the 1964 Helsinki declaration and its later amendments or comparable ethical standards. A waiver of informed consent was obtained for participants of this study, given the retrospective nature of the investigation $(\mathrm{BH}$ institutional review board number 2015-443).

\section{Results \\ All patients}

The final sample consisted of 1,574 patients with COPD who presented to the ED within 30 days of an index admission for COPD (Figure 1). Of these patients, 82.2\% $(n=1,294)$ were readmitted through the ED. Table 1 displays patient characteristics by readmission status. Multivariate logistic regression model revealed significant relationships between 30-day readmission and a number of patient characteristics (Table 2). For every single unit increase in Charlson score, the odds of 30-day readmission increased by 3.6 (95\% CI: 2.9-4.4). Prescribed outpatient COPD medications, including albuterol (odds ratio [OR]: 4.1; 95\% CI: 2.6-6.4), fluticasone/ salmeterol (OR: 2.3; 95\% CI: 1.3-4.2), inhaled steroids (OR: 3.8; 95\% CI: 1.3-10.7), and tiotropium (OR: 1.8; 95\% CI: 1.0-3.2), were found to be independent predictors of 30-day readmission through the ED. In addition, a chief complaint of breathing difficulty (OR: 1.7; 95\% CI: 1.1-2.6),

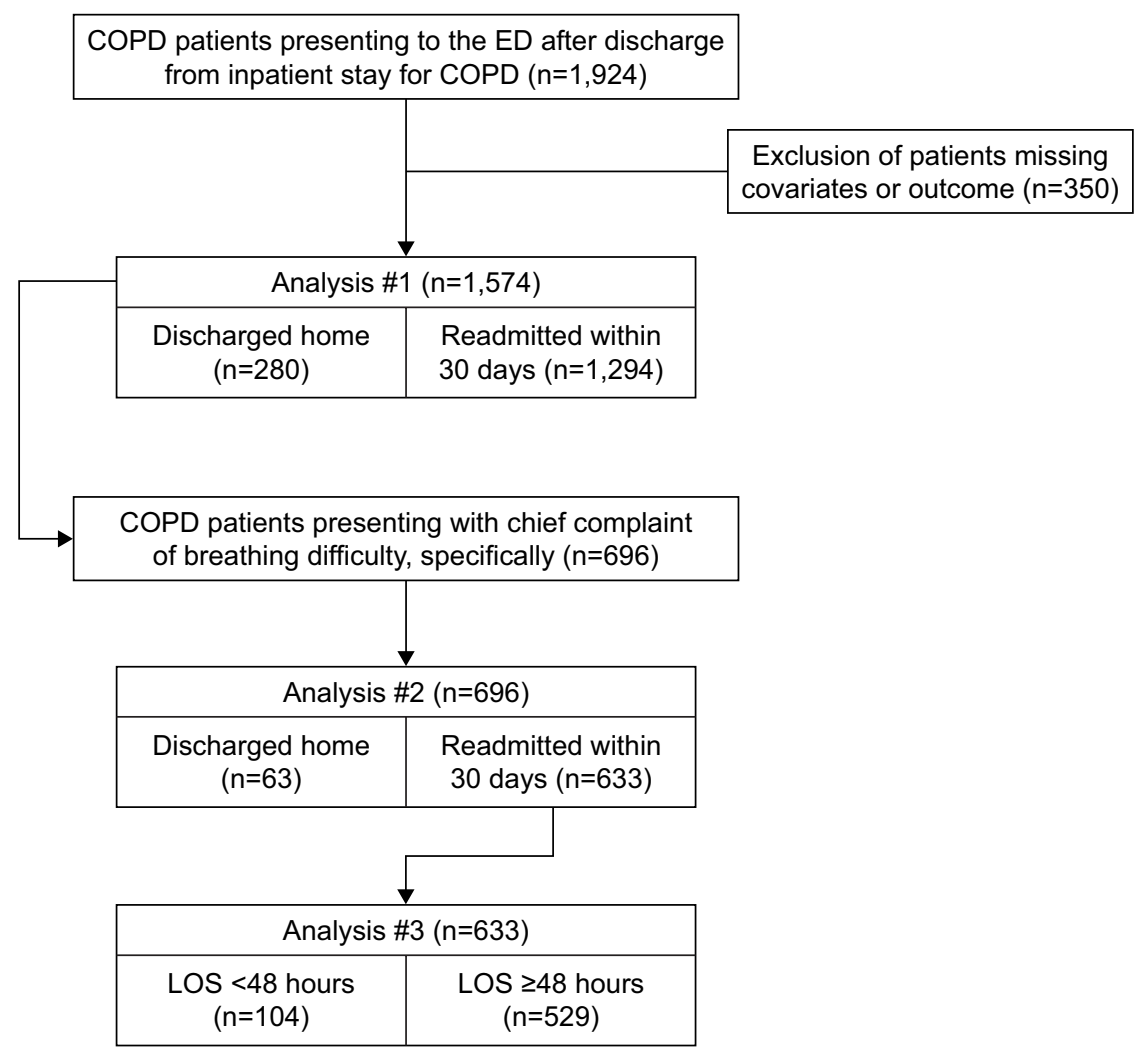

Figure I Study flow diagram.

Abbreviations: ED, emergency department; LOS, length of stay. 
Table I Demographic and clinical characteristics of COPD patients presenting to the ED by 30 -day readmission status

\begin{tabular}{|c|c|c|c|}
\hline Characteristics & $\begin{array}{l}\text { Discharged } \\
\text { home, } n=280\end{array}$ & $\begin{array}{l}\text { Readmitted, } \\
\mathrm{n}=I, 294\end{array}$ & P-value \\
\hline Female gender, $\mathrm{n}(\%)$ & $112(40.4)$ & $568(43.9)$ & 0.3 \\
\hline Age, mean (SD) & $69.6(12.6)$ & $73.3(11.8)$ & $<0.0001$ \\
\hline Number of inpatient admissions, previous year, mean (SD) & $0.9(I . I)$ & I.I (I.3) & 0.03 \\
\hline Time to re-presentation, mean (SD) & $13.7(8.5)$ & $13.9(8.6)$ & 0.73 \\
\hline LOS of first inpatient stay, mean (SD) & $5.1(4.4)$ & $5.9(4.9)$ & 0.02 \\
\hline \multicolumn{4}{|l|}{ Time of admission, $n(\%)$} \\
\hline Between 9 AM and 5 PM & $140(50.5)$ & $66 \mathrm{I}(5 \mathrm{I} . \mathrm{I})$ & 0.87 \\
\hline After hours & $137(49.5)$ & $633(48.9)$ & \\
\hline Time in ED (hours), mean (SD) & $6.2(6.0)$ & $6.8(4.5)$ & 0.04 \\
\hline \multicolumn{4}{|l|}{ Medication group, $\mathrm{n}(\%)$} \\
\hline Albuterol & $58(20.9)$ & $909(70.3)$ & $<0.0001$ \\
\hline Fluticasone/salmeterol & $21(7.6)$ & $464(35.9)$ & $<0.0001$ \\
\hline Inhaled steroids & $5(1.8)$ & $154(11.9)$ & $<0.000$ I \\
\hline Tiotropium & $23(8.3)$ & $465(35.9)$ & $<0.000$ I \\
\hline Pulse rate upon leaving ED, mean (SD) & $81.9(15.3)$ & $87.2(17.3)$ & $<0.0001$ \\
\hline Respiration rate upon leaving ED, mean (SD) & $18.7(2.4)$ & $20.1(4.3)$ & $<0.000$ I \\
\hline Oxygen saturation upon leaving ED (\%), mean (SD) & $96.5(3.3)$ & $96.4(3.5)$ & 0.51 \\
\hline Systolic BP upon leaving ED, mean (SD) & $130.4(19.7)$ & $\mid 27.5(2 \mid .8)$ & 0.04 \\
\hline Diastolic BP upon leaving ED, mean (SD) & $72.1(12.9)$ & $69.6(14.2)$ & 0.006 \\
\hline ABG was conducted in emergency room (yes), $n(\%)$ & $3(1.1)$ & $168(12.9)$ & $<0.000$ I \\
\hline BNP conducted in emergency room (yes), $n$ (\%) & $49(17.8)$ & $735(56.8)$ & $<0.000$ I \\
\hline \multicolumn{4}{|l|}{ Race, n (\%) } \\
\hline White & $194(70.0)$ & $947(73.2)$ & 0.2 \\
\hline Black & $48(17.3)$ & $|7|(\mid 3.2)$ & \\
\hline Other & $35(12.6)$ & $176(13.6)$ & \\
\hline \multicolumn{4}{|l|}{ Marital status, n (\%) } \\
\hline Single & $119(42.9)$ & $53 I(4 I)$ & 0.4 \\
\hline Married & $104(37.6)$ & $540(41.7)$ & \\
\hline Divorced/separated & $54(19.5)$ & $223(17.2)$ & \\
\hline Weight (kg), mean (SD) & $80.9(24.6)$ & $80.1(24.7)$ & 0.62 \\
\hline BMI, mean (SD) & $29.2(8.5)$ & $28.9(8.5)$ & 0.55 \\
\hline \multicolumn{4}{|l|}{ Smoking, n (\%) } \\
\hline Never & $28(10.1)$ & $140(10.8)$ & $<0.000$ I \\
\hline Quit & $112(40.4)$ & $799(61.8)$ & \\
\hline Not asked & $76(27.4)$ & $148(\mid 1.4)$ & \\
\hline Yes & $61(22.0)$ & $207(16.0)$ & \\
\hline Charlson score, mean (SD) & $0.6(1.1)$ & $3.2(2.2)$ & $<0.000$ I \\
\hline Tobacco pack years, mean (SD) & $18.0(30.8)$ & $24.1(32.9)$ & 0.005 \\
\hline Breathing room air in ED (yes), $n(\%)$ & $173(62.5)$ & $550(42.5)$ & $<0.0001$ \\
\hline Glasgow score upon leaving ED visit (=15), n (\%) & $253(91.3)$ & $\mathrm{I}, 143(88.3)$ & 0.15 \\
\hline \multicolumn{4}{|l|}{ Chief complaint, $n(\%)$} \\
\hline Breathing difficulty & $63(22.7)$ & $633(48.9)$ & $<0.000$ I \\
\hline Chest pain & $21(7.6)$ & $91(7.0)$ & \\
\hline Fatigue & $5(1.8)$ & $76(5.9)$ & \\
\hline Abdominal pain & $13(4.7)$ & $51(3.9)$ & \\
\hline Fall & $21(7.6)$ & $28(2.2)$ & \\
\hline Extremity edema & $9(3.3)$ & $4 \mid(32)$ & \\
\hline Blood sugar problem & $7(2.5)$ & $9(0.7)$ & \\
\hline Fever, nausea, and vomiting & $10(3.6)$ & $62(4.9)$ & \\
\hline Altered mental status & $3(1.1)$ & $36(2.8)$ & \\
\hline MSK complaint & $31(11.2)$ & $51(3.9)$ & \\
\hline Other & $94(33.9)$ & $216(16.7)$ & \\
\hline \multicolumn{4}{|l|}{ Insurance, $\mathrm{n}(\%)$} \\
\hline Medicare & $203(73.8)$ & $999(63.9)$ & 0.36 \\
\hline Medicaid & $25(9.1)$ & $93(7.2)$ & \\
\hline Commercial & $47(17.1)$ & $195(15.2)$ & \\
\hline Second LOS, mean (SD) & - & $6.4(7.6)$ & \\
\hline
\end{tabular}

Abbreviations: ABG, arterial blood gas; BMl, body mass index; BNP, B-type natriuretic peptide; BP, blood pressure; ED, emergency department; LOS, length of stay; MSK, musculoskeletal. 
Table 2 Multiple logistic regression results for COPD patients presenting to the ED by 30-day readmission status

\begin{tabular}{|c|c|c|}
\hline Parameters & $\begin{array}{l}\text { Odds of readmission } \\
\text { OR }(95 \% \mathrm{Cl})\end{array}$ & $P$-value \\
\hline$\overline{\text { Age }}$ & I.0 (0.99-I.0) & 0.56 \\
\hline Female gender & $0.9(0.6-1.3)$ & 0.43 \\
\hline \multicolumn{3}{|l|}{ Insurance status } \\
\hline Commercial & Ref & \\
\hline Medicaid & I.I (0.5-2.3) & 0.75 \\
\hline Medicare & $0.9(0.5-1.6)$ & 0.62 \\
\hline \multicolumn{3}{|l|}{ Race } \\
\hline White & Ref & \\
\hline Black & $0.6(0.3-1.0)$ & 0.12 \\
\hline Other & $0.8(0.5-1.5)$ & 0.74 \\
\hline Charlson score & $3.6(2.9-4.4)$ & $<0.001$ \\
\hline Length of first inpatient stay & $1.0(0.9-1.1)$ & 0.85 \\
\hline \multicolumn{3}{|l|}{ Medication type } \\
\hline Albuterol & $4 . I(2.6-6.4)$ & $<0.001$ \\
\hline Fluticasone/salmeterol & $2.3(1.4-4.2)$ & 0.005 \\
\hline Inhaled steroid & $3.8(1.3-10.7)$ & 0.01 \\
\hline Tiotropium & $1.8(1.0-3.2)$ & 0.05 \\
\hline \multicolumn{3}{|l|}{ Chief complaint } \\
\hline Chest pain & $0.9(0.4-1.9)$ & 0.80 \\
\hline Difficulty breathing & $1.7(1.1-2.6)$ & 0.02 \\
\hline $\begin{array}{l}\text { Number of inpatient admissions, } \\
\text { previous year }\end{array}$ & $0.9(0.8-1.1)$ & 0.35 \\
\hline \multicolumn{3}{|l|}{ Smoking status } \\
\hline Never & Ref & \\
\hline Not asked & $0.4(0.2-0.8)$ & 0.007 \\
\hline Quit & $0.9(0.5-1.8)$ & 0.07 \\
\hline Yes & $0.6(0.3-1.2)$ & $0.4 I$ \\
\hline \multicolumn{3}{|l|}{ Marital status } \\
\hline Single/widowed & Ref & \\
\hline Married & $0.9(0.6-1.5)$ & 0.42 \\
\hline Separated/divorced & $0.7(0.4-1.1)$ & 0.12 \\
\hline Time in the ED (hours) & $0.9(0.9-1.0)$ & 0.72 \\
\hline ABG test conducted in ER (yes/no) & $4.4(1.3-15.1)$ & 0.02 \\
\hline BNP test conducted in ER (yes/no) & $2.2(1.4-3.5)$ & $<0.001$ \\
\hline Pack years & $1.0(0.9-1.0)$ & 0.43 \\
\hline Systolic BP upon leaving ED & $0.9(0.9-1.0)$ & 0.61 \\
\hline Diastolic BP upon leaving ED & $1.0(0.9-1.0)$ & 0.37 \\
\hline
\end{tabular}

Abbreviations: $\mathrm{ABG}$, arterial blood gas; $\mathrm{BNP}$, B-type natriuretic peptide; $\mathrm{BP}$, blood pressure; ED, emergency department; OR, odds ratio; Ref, reference.

and ABG (OR: 4.4; 95\% CI: 1.3-15.1) and BNP (OR: 2.2; 95\% CI: 1.4-3.5) testing were associated with 30-day readmission $(\mathrm{c}$-statistic $=0.936)$.

\section{Breathing difficulty}

Out of the final sample, $44.2 \%(n=696)$ presented to the ED with a chief complaint of breathing difficulty. Of these patients, $90.9 \%(n=633)$ were readmitted through the ED (Table S1). Among patients who presented with breathing difficulty, our multivariate regression model revealed that Charlson score (OR: 2.3; 95\% CI: 1.7-3.2), albuterol utilization (OR: 7.2; 95\% CI: 3.2-16.3), being a former smoker (OR: 3.5 ; 95\% CI: 1.0-12.6), and having an increased pulse rate in the ED (OR: $1.0 ; 95 \%$ CI: 1.0-1.1) were independent predictors of readmission through the ED (Table S2; c-statistic $=0.936$ ).

\section{Readmission length}

Out of the 633 patients with breathing difficulty who were readmitted, 83.6\% ( $\mathrm{n}=529)$ had an LOS $\geq 48$ hours. Readmitted patients with an LOS $\geq 48$ hours remained in the hospital on an average of 8.1 days (Table S3). Multivariate logistic regression revealed that a longer LOS during the previous COPD inpatient stay (OR: 1.2; 95\% CI: 1.1-1.3) predicted a readmission length $\geq 48$ hours. Furthermore, a Glasgow score of 15 (OR: $0.1 ; 95 \%$ CI: $0.01-0.7$ ) was negatively associated with readmission length $($ Table S4; c-statistic $=0.762$ ).

\section{Discussion}

We observed that $82 \%$ of patients with COPD who presented to the ED within 30 days of an index admission for COPD were readmitted through the ED. Significant risk factors for 30-day readmission through the ED included Charlson score, prescribed outpatient COPD medications (albuterol, fluticasone/salmeterol, and inhaled steroids), a chief complaint of breathing difficulty, and the conduct of $A B G$ and BNP testing in the ED. Among patients with COPD who presented with breathing difficulty, $91 \%$ were readmitted. Outpatient albuterol utilization, smoking history, and an increased pulse rate were risk factors for readmission in this group. Among patients with COPD who were readmitted with breathing difficulty, $\sim 84 \%$ had a readmission stay $\geq 48$ hours, with an average LOS of 8 days. Risk factors for a readmission stay $\geq 48$ hours included previous COPD admission LOS and a Glasgow score of $<15$ in the ED.

Readmission events among patients with COPD are common, costly, and potentially preventable. Since incorporation of COPD into the MHRRP, there has been interest in identifying and mitigating the risk factors for readmission in patients with COPD. ${ }^{18,19}$ In 2003, Garcia-Aymerich et al published what has become a prominent study of risk factors for COPD readmission. Among 340 patients with COPD, $\geq 3$ admissions for COPD in the previous year, anticholinergic drug use, oral corticosteroid use, and long-term oxygen therapy significantly predicted readmission at 1 year, while forced expiratory volume in 1 second, oxygen tension, and higher levels of physical activity were protective. ${ }^{20}$ We found that outpatient COPD medications (albuterol, fluticasone/salmeterol, and inhaled steroids) were associated with 30-day readmission through the $\mathrm{ED}$. This relationship is likely explained by the severity of a patient's baseline disease. 
In other words, a patient with more severe baseline COPD is likely prescribed a more extensive and complex medication regimen consistent with standard therapy, and is sicker and at increased need for readmission than the patients who are not prescribed such medications. Outpatient albuterol use alone may also be a reflection of uncontrolled disease after discharge in these patients.

In 2015, Genao et al published a claims-based analysis examining the risk factors for repeat acute care visits within 30 days of an index COPD admission among 18,306 patients. The authors identified age $\geq 80$ years, dual-eligibility status, long-term oxygen use, and several pulmonary comorbidities as risk factors for repeat acute care visits. ${ }^{21} \mathrm{We}$ did not examine specific pulmonary comorbidities, but our findings are in agreement that multimorbidity drives COPD readmission. In addition, our study confirms breathing difficulty as a risk factor for readmission. ${ }^{22,23}$ However, unlike previous research, we found that gender, age, insurance, and number of inpatient admissions over the previous year were not associated with 30-day readmission. ${ }^{24,25}$ Interestingly, we did observe an association between ABG and BNP testing and 30-day readmission through the ED. ABG testing is an important clinical tool used to dictate emergent treatment, especially in critically ill patients; therefore, it is not surprising that its use would be associated with readmission. In this setting, ABG testing likely serves as a marker for severe respiratory disease and/or identifies patients presenting with a clinical impression of respiratory distress, rather than serving as a laboratory test that independently predicts readmission. In the acute care setting, BNP is used to distinguish dyspnea secondary to cardiac vs other etiologies, and is often used in the ED to identify acute exacerbations of congestive heart failure. We found that BNP testing was associated with 30-day readmission among all patients, but not when the sample was limited to patients who presented with breathing difficulty. The latter finding is likely explained by the fact that although BNP testing can be used to help determine the etiology of dyspnea among patients who present to the ED, it is not considered to have a profound impact on hospitalization rates or patient outcomes, ${ }^{26}$ and in our case did not significantly impact the decision to readmit. Comorbid congestive heart failure may explain our observed relationship between BNP testing and 30-day readmission in all patients, regardless of presenting chief complaint. Although requiring additional study, this finding could also represent improper and/or overuse of BNP testing in patients with COPD who present to the ED for non-dyspnea reasons, resulting in an unwarranted increased tendency among providers to readmit.
The ED has been identified as a potential setting to target COPD readmission reduction efforts. ${ }^{6}$ We agree with this notion as $82 \%$ and $91 \%$ of patients with COPD who presented to the ED for any cause or with breathing difficulty, specifically, were readmitted to the hospital through ED within 30 days in our sample. Sweeping COPD readmission reduction programs have proven to be largely ineffective to date. ${ }^{27}$ However, there is promise in targeting specific subgroups of patients with COPD to reduce overall readmission rates. ${ }^{27}$ In accordance with this thinking, we limited our sample to patients with COPD presenting to the ED with breathing difficulty and then subdivided this group of patients by subsequent readmission length.

Only $44 \%$ of the patients in our study presented to the ED with breathing difficulty; $56 \%$ presented due to reasons such as chest pain, fatigue, abdominal pain, musculoskeletal complaint, or blood sugar problem. A significant proportion of this $56 \%$ could likely benefit from an outpatient primary care visit immediately after discharge or discharge directly to a subacute rehab facility where low-risk health complaints could be addressed, and thereby potentially avoid needing to visit the ED. Almost $91 \%$ of patients with COPD who presented to the ED with breathing difficulty were readmitted to the hospital. Among these patients, we found the following to predict 30-day readmission: outpatient albuterol utilization, being a former smoker, having a higher Charlson score, and having an increased pulse rate in the ED. These risk factors may be mitigated through better access to and follow-up with generalists and specialists to improve management of comorbid conditions as well as better stabilization and normalization of patients in the ED.

One intervention that may prove to be beneficial in preventing re-presentation to the ED is an early and automatic outpatient visit after discharge. If patients with COPD can be seen in person or connected with using telehealth modalities within 48 hours of discharge, this would provide clinicians with an opportunity to clinically assess the patient, evaluate the effect of medication changes made during the previous admission, monitor medication adherence patterns, and discuss other non-COPD-related health concerns the patient has. The ultimate goal of this intervention would be to prevent re-presentation to the ED to begin with. Although such an intervention may be difficult for individual attending physicians, a supervised resident or associate provider clinic and workforce could potentially make a significant impact in this arena.

In an effort to identify patients who could have been safely discharged home or managed in the ED longer rather 
than being readmitted, we examined the LOS for readmitted patients with COPD with breathing difficulty. We found that $83.6 \%$ of readmitted patients had an LOS of $\geq 48$ hours, with an average LOS of 8 days. LOS of their index COPD admission and Glasgow score in the ED predicted the length of their second inpatient stay. The index COPD admission LOS of the $16.4 \%$ of patients with a second LOS $<48$ hours was 1.3 days. These observations suggest that there are two distinct populations of patients with COPD who are readmitted within 30 days: those likely requiring minimal therapy and those requiring more advanced management and a justifiable, increased LOS. Different readmission reduction interventions can be designed to target these two groups, and prior admission LOS may be a useful piece of information for the readmission decision-making process in the ED.

In today's climate of bundled payments and MHRRP, having $82 \%-91 \%$ of patients with COPD readmitted through the ED within 30 days of an inpatient discharge is a quality of care and financial issue for hospitals. From an equally important perspective, we have shown that $9 \%-18 \%$ of patients with COPD who present to the ED are discharged home without being readmitted. These patients are healthier and have less comorbidity than patients who are readmitted to the hospital, suggesting that these individuals presented to the ED unnecessarily. We have also shown that a large percentage of patients with COPD are readmitted through the ED, but more than half of the time $(56 \%)$ with complaints other than breathing difficulty. Even if patients present with troubled breathing, $16 \%$ are readmitted to the hospital for $<48$ hours. These results may speak to the need for better education at discharge regarding when it is appropriate for a COPD patient to present to the ED vs primary care provider with a health concern after discharge. Our findings may also provide additional evidence for the role of immediate outpatient follow-up after discharge or discharge to a subacute rehab facility rather than directly home. Furthermore, given the high rate of readmissions observed in this study, the ED is a logical setting in which to target certain COPD readmission reduction efforts that identify patients who would not benefit from readmission or could be managed in an alternative manner, such as more thoughtful monitoring in an observation unit. ED and admitting providers should be willing to examine their decision making regarding readmission to the hospital, significant risk factors for readmission, and be willing to mitigate potentially modifiable ones, such as unstable vital signs and potentially unnecessary testing.

Strengths of our study include a large sample size and the use of EHR data to obtain a robust set of variables.
These aspects help improve the study's generalizability. The weakness is our use of ICD-9-CM codes to identify patients with COPD. The sensitivity of ICD-9-CM codes for COPD is low and ranges from $12 \%$ to $25 \%$, whereas the specificity is $>99 \% .{ }^{28}$ Our study may suffer from an increased number of false negatives, which inappropriately undercounted COPD hospitalizations. We may also have missed patients who presented to unaffiliated hospitals. In addition, despite our use of EHR data, we were missing important covariates such as forced expiratory volume in 1 second, COPD medication adherence, physical activity level, quality of life, a primary care provider visit before ED presentation, and the subjective assessment of the patient's clinical picture. In particular, lack of data related to functional assessment and disease severity (frequent exacerbations vs nonfrequent exacerbations) is an important limitation of this study that needs to be noted, as predictors of readmission are likely influenced by underlying disease activity and comorbidities. We attempted to address this limitation by controlling for the number of inpatient admissions over the previous year, Charlson score, and smoking status. However, proxies for disease severity and comorbidity burden likely underestimate the impact of these factors on readmission risk.

\section{Conclusion}

Our findings demonstrate the need for intensive outpatient monitoring, evaluation, and follow-up after discharge to help prevent re-presentation to the $\mathrm{ED}$, as practically all patients with COPD who re-present to the ED are readmitted to the hospital and for a variety of clinical complaints. Among those patients with COPD who present with breathing difficulty, improved decision support algorithms and alternative management strategies are needed to identify and intervene on the subgroup of patients who require $<48$-hour LOS.

\section{Acknowledgments}

Charlotte E Ward is supported by the training grant T32 HS000084 awarded to Northwestern University and the University of Chicago, by the Agency of Healthcare Research and Quality, as part of her doctoral program.

Dr Michael Rezaee and Mr Daniel Rezaee are siblings. However, Dr Michael Rezaee is a physician based in southeastern Michigan, while Mr Daniel Rezaee is a population health specialist based in Boston, Massachusetts. All authors declare that their relationship as siblings did not impact the conduct of this study or the development of this manuscript in any way. 


\section{Disclosure}

The authors report no conflicts of interest in this work.

\section{References}

1. Centers for Disease Control and Prevention. Chronic Obstructive Pulmonary Disease (COPD). 2014. Available from: http://www.cdc.gov/ copd/data.htm. Accessed February 4, 2016.

2. American Lung Association. COPD Fact Sheet. 2011. Available from: http://www.lung.org/lung-disease/copd/resources/facts-figures/COPDFact-Sheet.html. Accessed February 4, 2016.

3. Ford ES. Hospital discharges, readmissions, and ED visits for COPD or bronchiectasis among US adults: findings from the nationwide inpatient sample 2001-2012 and Nationwide Emergency Department Sample 2006-2011. Chest. 2015;147(4):989-998.

4. Elixhauser A, Hu DA, Podulka J. Readmissions for Chronic Obstructive Pulmonary Disease, 2008. Statistical Brief \#121. Healthcare Cost and Utilization Project 2011. Available from: http://www.hcup-us.ahrq. gov/reports/statbriefs/sb121.pdf. Accessed December 23, 2016.

5. Prieto-Centurion V, Markos MA, Ramey NI, et al. Interventions to reduce rehospitalizations after chronic obstructive pulmonary disease exacerbations. A systematic review. Ann Am Thorac Soc. 2014;11(3): 417-424.

6. American College of Emergency Physicians. Medicare's hospital readmission reduction program FAQ. 2015. Available from: http://www. acep.org/Physician-Resources/Practice-Resources/Administration/ Financial-Issues-/-Reimbursement/Medicare-s-Hospital-ReadmissionReduction-Program-FAQ/. Accessed February 4, 2016.

7. Garcia-Gutierrez S, Quintana JM, Aguirre U, et al; Investigación en Resultados y Servicios Sanitarios (IRYSS) COPD Group. Explicit criteria for hospital admission in exacerbations of chronic obstructive pulmonary disease. Int J Tuberc Lung Dis. 2011;15(5):680-686.

8. Garcia-Gutierrez S, Quintana JM, Barrio I, et al. Application of appropriateness criteria for hospitalization in COPD exacerbation. Intern Emerg Med. 2013;8(4):349-357.

9. Quintana JM, Esteban C, Barrio I, et al; IRYSS-COPD Group. The IRYSS-COPD appropriateness study: objectives, methodology, and description of the prospective cohort. BMC Health Serv Res. 2011; 11:322.

10. Rowe BH, Bhutani M, Stickland MK, Cydulka R. Assessment and management of chronic obstructive pulmonary disease in the emergency department and beyond. Expert Rev Respir Med. 2011;5(4): 549-559.

11. Garcia-Aymerich J, Monso E, Marrades RM, et al. Risk factors for hospitalization for a chronic obstructive pulmonary disease exacerbation. EFRAM study. Am J Respir Crit Care Med. 2001;164(6): 1002-1007.

12. Amalakuhan B, Kiljanek L, Parvathaneni A, Hester M, Cheriyath P, Fischman D. A prediction model for COPD readmissions: catching up, catching our breath, and improving a national problem. $J$ Community Hosp Intern Med Perspect. 2012;2(1):10.3402/jchimp.v2i1.9915.
13. Collins GS, Reitsma JB, Altman DG, Moons KG. Transparent reporting of a multivariable prediction model for individual prognosis or diagnosis (TRIPOD): the TRIPOD statement. Br J Surg. 2015;102(3):148-158.

14. Vandenbroucke JP, von Elm E, Altman DG, et al. Strengthening the Reporting of Observational Studies in Epidemiology (STROBE): explanation and elaboration. PLoS Med. 2007;4(10):e297.

15. Bendel RB, Afifi AA. Comparison of stopping rules in forward "Stepwise" regression. J Am Stat Assoc. 1977;72(357):46-53.

16. Mickey RM, Greenland S. The impact of confounder selection criteria on effect estimation. Am J Epidemiol. 1989;129(1):125-137.

17. Harrell F. Regression Modeling Strategies: With Applications to Linear Models, Logistic Regression, and Survival Analysis. NY, USA: Springer-Verlag New York; 2001.

18. US Centers for Medicare \& Medicaid Services. Hospital Readmissions Reduction Program. 2016. Available from: https://www.medicare. gov/hospitalcompare/readmission-reduction-program.html. Accessed December 23, 2016.

19. Glaser JB, Pau D, Maniatis T. Differential risk factors for chronic obstructive pulmonary disease 30-day readmissions according to indication for readmission. Ann Am Thorac Soc. 2016;13(3):447.

20. Garcia-Aymerich J, Farrero E, Felez MA, Izquierdo J, Marrades RM, Anto JM; Estudi del Factors de Risc d'Agudització de la MPOC investigators. Risk factors of readmission to hospital for a COPD exacerbation: a prospective study. Thorax. 2003;58(2):100-105.

21. Genao L, Durheim MT, Mi X, Todd JL, Whitson HE, Curtis LH. Early and long-term outcomes of older adults after acute care encounters for chronic obstructive pulmonary disease exacerbation. Ann Am Thorac Soc. 2015;12(12):1805-1812.

22. Bahadori K, FitzGerald JM. Risk factors of hospitalization and readmission of patients with COPD exacerbation systematic review. Int $J$ Chron Obstruct Pulmon Dis. 2007;2(3):241-251.

23. Cao Z, Ong KC, Eng P, Tan WC, Ng TP. Frequent hospital readmissions for acute exacerbation of COPD and their associated factors. Respirology. 2006;11(2):188-195.

24. Pouw EM,Ten Velde GP, Croonen BH, Kester AD, Schols AM, WoutersEF. Early non-elective readmission for chronic obstructive pulmonary disease is associated with weight loss. Clin Nutr. 2000;19(2):95-99.

25. Groenewegen KH, Schols AM, Wouters EF. Mortality and mortalityrelated factors after hospitalization for acute exacerbation of COPD. Chest. 2003;124(2):459-467.

26. Carpenter CR, Keim SM, Worster A, Rosen P, BEEM (Best Evidence in Emergency Medicine). Brain natriuretic peptide in the evaluation of emergency department dyspnea: is there a role? J Emerg Med. 2012; 42(2):197-205.

27. Berry CE, Kalhan R. Chronic obstructive pulmonary disease rehospitalization. A big problem that now needs solutions. Ann Am Thorac Soc. 2015; 12(12):1741-1742.

28. Stein BD, Bautista A, Schumock GT, et al. The validity of International classification of diseases, ninth revision, clinical modification diagnosis codes for identifying patients hospitalized for COPD exacerbations. Chest. 2012;141(1):87-93. 


\section{Supplementary materials}

Table SI Demographic and clinical characteristics of COPD patients presenting to the ED with breathing difficulty by 30 -day readmission status

\begin{tabular}{|c|c|c|c|}
\hline Characteristics & $\begin{array}{l}\text { Discharged } \\
\text { home, } n=63\end{array}$ & $\begin{array}{l}\text { Readmitted, } \\
n=633\end{array}$ & $P$-value \\
\hline Female gender, $\mathrm{n}(\%)$ & $24(38.1)$ & $307(48.5)$ & 0.11 \\
\hline Age, mean (SD) & $66.0(12.9)$ & $72.8(11.5)$ & $<0.000$ I \\
\hline Number of inpatient admissions, previous year, mean (SD) & $1.3(1.4)$ & I.I (I.3) & 0.28 \\
\hline Time to re-presentation, mean (SD) & $14.6(8.5)$ & | $4.1(85.5)$ & 0.65 \\
\hline LOS of first inpatient stay, mean (SD) & $5.0(4.6)$ & $5.6(4.8)$ & 0.38 \\
\hline \multicolumn{4}{|l|}{ Time of admission, n (\%) } \\
\hline Between 9 AM and 5 PM & $32(50.8)$ & $297(46.9)$ & 0.56 \\
\hline After hours & $31(49.2)$ & $336(53.1)$ & \\
\hline Time in ED (hours), mean (SD) & $6.6(6.5)$ & $6.5(4.1)$ & 0.77 \\
\hline \multicolumn{4}{|l|}{ Medication group, n (\%) } \\
\hline Albuterol & $14(22.2)$ & $478(75.5)$ & $<0.000 \mathrm{I}$ \\
\hline Fluticasone/salmeterol & $5(7.9)$ & $252(39.8)$ & $<0.0001$ \\
\hline Inhaled steroids & $2(3.2)$ & $76(12.0)$ & 0.03 \\
\hline Tiotropium & $5(7.9)$ & $26 I(4 I .2)$ & $<0.000$ I \\
\hline Pulse rate upon leaving ED, mean (SD) & $84.9(15.5)$ & $91.0(17.1)$ & 0.007 \\
\hline Respiration rate upon leaving ED, mean (SD) & $19.6(3.4)$ & $21.1(4.8)$ & 0.02 \\
\hline Oxygen saturation upon leaving ED (\%), mean (SD) & $96.6(2.3)$ & $96.2(4.3)$ & $0.4 \mathrm{I}$ \\
\hline Systolic BP upon leaving ED, mean (SD) & I27.7 (I8.8) & $127.4(21.8)$ & 0.93 \\
\hline Diastolic BP upon leaving ED, mean (SD) & $69.9(13.2)$ & $69.4(14.0)$ & 0.76 \\
\hline ABG was conducted in emergency room (yes), $n$ (\%) & I ( $(1.6)$ & $115(18.2)$ & 0.0008 \\
\hline BNP conducted in emergency room (yes), n (\%) & $25(39.7)$ & $448(70.8)$ & $<0.0001$ \\
\hline Breathing room air in ED (yes), n (\%) & $34(53.9)$ & $212(33.5)$ & 0.001 \\
\hline \multicolumn{4}{|l|}{ Race, n (\%) } \\
\hline White & 45 (7I.4) & $463(73.1)$ & 0.15 \\
\hline Black & $13(20.6)$ & $83(13.1)$ & \\
\hline Other & $5(7.9)$ & $87(13.7)$ & \\
\hline \multicolumn{4}{|l|}{ Marital status, n (\%) } \\
\hline Single & $31(49.2)$ & $238(37.6)$ & 0.08 \\
\hline Married & I8 (28.6) & $273(43.1)$ & \\
\hline Divorced/separated & $14(22.2)$ & $122(19.3)$ & \\
\hline Weight (kg), mean (SD) & $79.3(23.1)$ & $80.4(24.9)$ & 0.75 \\
\hline BMI, mean (SD) & $28.7(8.0)$ & $28.7(8.5)$ & 0.98 \\
\hline \multicolumn{4}{|l|}{ Smoking, n (\%) } \\
\hline Never & $8(12.7)$ & $50(7.9)$ & $<0.000$ I \\
\hline Quit & $19(30.2)$ & $414(65.4)$ & \\
\hline Not asked & $17(26.9)$ & $62(9.8)$ & \\
\hline Yes & $19(30.2)$ & $107(16.9)$ & \\
\hline Charlson score, mean (SD) & I.I (I.2) & $3.1(2.1)$ & $<0.000$ I \\
\hline Tobacco pack years, mean (SD) & $19.6(30.4)$ & $27.3(34.7)$ & 0.09 \\
\hline Glasgow score upon leaving ED visit (=15), n (\%) & $59(9.7)$ & $579(91.5)$ & 0.55 \\
\hline \multicolumn{4}{|l|}{ Insurance, $\mathrm{n}(\%)$} \\
\hline Medicare & $45(73.6)$ & $478(76.1)$ & 0.72 \\
\hline Medicaid & $4(6.5)$ & $44(7.0)$ & \\
\hline Commercial & $13(20.9)$ & $106(16.9)$ & \\
\hline Second LOS, mean (SD) & - & $6.9(8.4)$ & \\
\hline
\end{tabular}

Abbreviations: ABG, arterial blood gas; BMI, body mass index; BNP, B-type natriuretic peptide; BP, blood pressure; ED, emergency department; LOS, length of stay. 
Table S2 Multiple logistic regression results for COPD patients presenting to the ED with breathing difficulty by 30 -day readmission status

\begin{tabular}{|c|c|c|}
\hline Parameters & $\begin{array}{l}\text { Odds of readmission } \\
\text { OR }(95 \% \mathrm{Cl})\end{array}$ & $P$-value \\
\hline Age & $1.0(0.99-1.0)$ & 0.17 \\
\hline Female gender & I.3 (0.6-2.6) & 0.55 \\
\hline \multicolumn{3}{|l|}{ Race } \\
\hline White & Ref & 0.61 \\
\hline Black & $1.0(0.4-2.7)$ & 0.36 \\
\hline Other & $1.8(0.5-6.2)$ & \\
\hline Charlson score & $2.3(1.7-3.2)$ & $<0.0001$ \\
\hline \multicolumn{3}{|l|}{ Medication type } \\
\hline Albuterol & $7.2(3.2-16.31)$ & $<0.001$ \\
\hline Fluticasone/salmeterol & $2.7(0.9-8.4)$ & 0.08 \\
\hline Inhaled steroid & $1.9(10.2)$ & 0.43 \\
\hline Tiotropium & $2.0(0.7-6.3)$ & 0.22 \\
\hline Number of inpatient admissions, previous year & $0.8(0.7-1.1)$ & 0.13 \\
\hline \multicolumn{3}{|l|}{ Smoking status } \\
\hline Never & Ref & \\
\hline Not asked & $0.6(0.2-2.3)$ & 0.02 \\
\hline Quit & $3.5(0.9-12.6)$ & 0.008 \\
\hline Yes & $2.3(0.6-8.4)$ & 0.19 \\
\hline \multicolumn{3}{|l|}{ Marital status } \\
\hline Single/widowed & Ref & \\
\hline Married & $1.7(0.7-3.9)$ & 0.39 \\
\hline Separated/divorced & $1.4(0.6-3.6)$ & 0.84 \\
\hline ABG test conducted (yes/no) & $6.6(0.7-44.9)$ & 0.09 \\
\hline BNP conducted in emergency room (yes) & $1.6(0.8-3.4)$ & 0.19 \\
\hline Breathing room air in ED (yes) & $0.6(0.3-1.2)$ & 0.15 \\
\hline Pack years & $0.9(0.9-1.0)$ & 0.45 \\
\hline Pulse rate upon leaving ED & $1.0(1.0-1.1)$ & 0.02 \\
\hline Respiration rate upon leaving ED & $1.0(0.9-1.1)$ & 0.73 \\
\hline
\end{tabular}

Abbreviations: ABG, arterial blood gas; BNP, B-type natriuretic peptide; BP, blood pressure; ED, emergency department; OR, odds ratio; Ref, reference. 
Table S3 Demographic and clinical characteristics of COPD patients readmitted through the ED with breathing difficulty by readmission length

\begin{tabular}{|c|c|c|c|}
\hline Characteristics & $\begin{array}{l}\text { Length }<48 \text { hours, } \\
\mathrm{n}=104\end{array}$ & $\begin{array}{l}\text { Length } \geq 48 \text { hours, } \\
n=529\end{array}$ & $P$-value \\
\hline Female gender, $\mathrm{n}(\%)$ & $58(55.8)$ & $249(47.1)$ & 0.11 \\
\hline Age, mean (SD) & $68.8(13.1)$ & $73.5(10.9)$ & 0.0001 \\
\hline Number of inpatient admissions, previous year, mean (SD) & $0.9(0.8)$ & $1.2(1.4)$ & 0.04 \\
\hline Time to re-presentation, mean (SD) & $14.7(9.2)$ & $13.9(8.3)$ & 0.44 \\
\hline LOS of first inpatient stay, mean (SD) & $3.8(3.0)$ & $5.9(5.0)$ & $<0.0001$ \\
\hline \multicolumn{4}{|l|}{ Time of admission, $n$ (\%) } \\
\hline Between 9 AM and 5 PM & $48(46.2)$ & $249(47.1)$ & \multirow[t]{2}{*}{0.86} \\
\hline After hours & $56(53.9)$ & $280(52.9)$ & \\
\hline Time in ED (hours), mean (SD) & $7.1(4.5)$ & $6.4(4.1)$ & 0.12 \\
\hline \multicolumn{4}{|l|}{ Medication group, n (\%) } \\
\hline Albuterol & 79 (75.9) & $399(75.4)$ & 0.91 \\
\hline Fluticasone/salmeterol & $42(40.4)$ & $210(39.1)$ & 0.9 \\
\hline Inhaled steroids & II (I0.6) & $65(12.3)$ & 0.62 \\
\hline Tiotropium & $4 \mathrm{I}(39.4)$ & $220(4 I .6)$ & 0.68 \\
\hline Pulse rate upon leaving ED, mean (SD) & $88.4(17.8)$ & 91.5 (16.9) & 0.09 \\
\hline Respiration rate upon leaving ED, mean (SD) & $19.9(4.2)$ & $21.3(4.9)$ & 0.007 \\
\hline Oxygen saturation upon leaving ED (\%), mean (SD) & $96.2(2.5)$ & $96.2(4.6)$ & 0.99 \\
\hline Systolic BP upon leaving ED, mean (SD) & $132.4(22.1)$ & $126.5(21.7)$ & 0.01 \\
\hline Diastolic BP upon leaving ED, mean (SD) & $72.7(13.2)$ & $68.8(14.1)$ & 0.01 \\
\hline ABG was conducted in emergency room (yes), n (\%) & $14(13.5)$ & $101(19.1)$ & 0.17 \\
\hline Breathing room air in ED (yes), $\mathrm{n}(\%)$ & $48(46.2)$ & $164(31.0)$ & 0.003 \\
\hline \multicolumn{4}{|l|}{ Race, n (\%) } \\
\hline White & $70(67.3)$ & $393(74.3)$ & \multirow[t]{3}{*}{0.27} \\
\hline Black & $15(14.4)$ & $68(12.9)$ & \\
\hline Other & $19(18.3)$ & $68(12.9)$ & \\
\hline \multicolumn{4}{|l|}{ Marital status, n (\%) } \\
\hline Single & $41(39.4)$ & $197(37.2)$ & \multirow[t]{3}{*}{0.82} \\
\hline Married & $42(40.4)$ & $231(43.7)$ & \\
\hline Divorced/separated & $21(20.2)$ & $100(18.9)$ & \\
\hline Weight (kg), mean (SD) & $80.2(23.9)$ & $80.5(25.2)$ & 0.9 \\
\hline BMI, mean (SD) & $28.73(8.1)$ & $28.7(8.6)$ & 0.99 \\
\hline \multicolumn{4}{|l|}{ Smoking, n (\%) } \\
\hline Never & $6(5.8)$ & $44(8.3)$ & \multirow[t]{4}{*}{0.002} \\
\hline Quit & $58(55.8)$ & $356(67.3)$ & \\
\hline Not asked & $9(8.7)$ & $53(10.0)$ & \\
\hline Yes & $31(29.8)$ & $76(14.4)$ & \\
\hline Charlson score, mean (SD) & $2.6(2.0)$ & $3.2(2.1)$ & 0.006 \\
\hline Tobacco pack years, mean (SD) & $24.3(30.5)$ & $27.9(35.5)$ & 0.33 \\
\hline Glasgow score upon leaving ED visit (=I5), n (\%) & $103(99.0)$ & $476(89.9)$ & 0.003 \\
\hline \multicolumn{4}{|l|}{ Insurance, $\mathrm{n}(\%)$} \\
\hline Medicare & $67(65.1)$ & $4 I I(78.3)$ & \multirow[t]{3}{*}{0.02} \\
\hline Medicaid & II (I0.7) & $33(6.3)$ & \\
\hline Commercial & $25(24.3)$ & $81(15.4)$ & \\
\hline Second LOS, mean (SD) & $1.3(0.5)$ & $8.1(8.2)$ & $<0.000$ I \\
\hline
\end{tabular}

Abbreviations: ABG, arterial blood gas; BMI, body mass index; BP, blood pressure; ED, emergency department; LOS, length of stay. 
Table S4 Multiple logistic regression results for COPD patients presenting to the ED with breathing difficulty by 30 -day readmission length $\geq 48$ hours

\begin{tabular}{|c|c|c|}
\hline Parameters & $\begin{array}{l}\text { Odds of readmission } \\
\text { OR }(95 \% \mathrm{Cl})\end{array}$ & $P$-value \\
\hline Age & $1.0(0.9-1.1)$ & 0.13 \\
\hline Female gender & $0.7(0.4-1.1)$ & 0.15 \\
\hline \multicolumn{3}{|l|}{ Insurance status } \\
\hline Commercial & Ref & \\
\hline Medicaid & $1.2(0.5-2.9)$ & 0.84 \\
\hline Medicare & $1.2(0.6-2.2)$ & 0.82 \\
\hline Charlson score & $1.1(0.9-1.2)$ & 0.11 \\
\hline Length of first inpatient stay (days) & $1.2(1.1-1.3)$ & 0.001 \\
\hline Breathing room air in ED (yes) & $0.8(0.5-1.3)$ & 0.41 \\
\hline Glasgow score upon leaving ED visit $(=15)$ & $0.1(0.01-0.7)$ & 0.02 \\
\hline Number of inpatient admissions, previous year & $1.3(0.9-1.6)$ & 0.06 \\
\hline \multicolumn{3}{|l|}{ Smoking status } \\
\hline Never & Ref & \\
\hline Not asked & $0.8(0.2-2.9)$ & 0.72 \\
\hline Quit & $0.6(0.3-2.2)$ & 0.87 \\
\hline Yes & $0.5(0.2-1.5)$ & 0.09 \\
\hline \multicolumn{3}{|l|}{ Marital status } \\
\hline Single/widowed & Ref & \\
\hline Married & $1.3(0.7-2.2)$ & 0.44 \\
\hline Separated/divorced & I.I (0.6-2.I) & 0.95 \\
\hline Time in the ED (hours) & $0.9(0.9-1.0)$ & 0.14 \\
\hline ABG test conducted (yes/no) & I.I $(0.6-2.1)$ & 0.79 \\
\hline Pulse rate upon leaving ED, mean (SD) & $1.0(0.9-1.0)$ & 0.41 \\
\hline Respiration rate upon leaving ED, mean (SD) & I.I $(0.9-1.0)$ & 0.08 \\
\hline Systolic BP upon leaving ED, mean (SD) & $0.9(0.9-1.0)$ & 0.17 \\
\hline Diastolic BP upon leaving ED, mean (SD) & $0.9(0.9-1.0)$ & 0.79 \\
\hline
\end{tabular}

Abbreviations: ABG, arterial blood gas; BP, blood pressure; ED, emergency department; OR, odds ratio; Ref, reference.

\section{Publish your work in this journal}

The International Journal of COPD is an international, peer-reviewed journal of therapeutics and pharmacology focusing on concise rapid reporting of clinical studies and reviews in COPD. Special focus is given to the pathophysiological processes underlying the disease, intervention programs, patient focused education, and self management protocols.

\section{Dovepress}

This journal is indexed on PubMed Central, MedLine and CAS. The manuscript management system is completely online and includes a very quick and fair peer-review system, which is all easy to use. Visit $\mathrm{http} / / / \mathrm{www}$.dovepress.com/testimonials.php to read real quotes from published authors. 